\title{
Short Note \\ Dualistic development and economic benefits: Experience from Community Forestry in Nepal
}

\author{
A. R. Sharma ${ }^{1 *}$ and R. B. Dangi ${ }^{1}$
}

\begin{abstract}
1most one third of the forest areas (1.71 $\triangle$ million hectares) throughout Nepal has been handed over to the local communities as community forests for ensuring the communities primarily to fulfill their basic needs of forestry products, besides their active participation on conserving biodiversity, and instigating social development at local level. More than 18,000 Community Forest User Groups (CFUGs) have been managing forests throughout the country and implementing different programmes related to forest conservation and livelihoods improvement. With wide spread community forestry, there is dilemma regarding further development of community forestry: Should the future course be "traditional sector enrichment" or "modern sector enlargement"? With this backdrop, the authors resort to give introduction of this paper to our readers.
\end{abstract}

This paper analyses how community forestry can affect income distribution in a dualistic economy when aid to one sector induces effect on the other. It further discusses how development fund should be channeled in community forestry keeping in mind the dualistic development. The economy is comprised of a modern sector mainly concentrated in urban areas and have export focus while traditional sector is predominated by agriculture often termed as "backward sector". Suppose, a development fund originating from the national treasure or from foreign aid mainly streaming from development partners, is made available for use in either of the two ways in community forestry: (1) to expand production and employment in the economy's modern sector (a process termed as modern sector enlargement) for hypothetical example: AUSAID assistance to establish a pole treatment plant at Panchkhal in Kavre District of Central Nepal with export focus or (2) to enhance productivity in the domestic sector (a process termed as traditional sector enrichment, for example, say DFID support to improve agriculture through the use of compost making use of leaf litters collected from community forests).

This paper dwells on the possible effect on income distribution on dualistic development and without spearheading a specific approach, intends to garner a policy discourse on the stylized and dualistic development approach in community forestry.

Nepal's ex-Finance Minister in his budget speech of Fiscal year 2013-14 has vowed to transform Nepal into a developing country by the year 2022 , that demands a renewed dialogue on future pathway of community forestry (GoN, 2013).

\section{Methodology}

This paper is mainly based on the field experiences of the authors, who worked in different districts of Nepal at the initial development stages of community forestry. The two examples, namely pole treatment plant and compost making using the leaf-litters are two case studies that represent modern sector enlargement and traditional sector enrichment respectively. The paper is mainly based on the stylized typology used by Gary (1992) and is based on the theoretical framework, mainly to assess impact of dualistic development on income distribution.

\section{Discussion}

As already mentioned, in this short paper, the authors have used Gary Fields' stylized development typologies (Todaro and Smith, 2004) to explain shifting of Lorenz curves and consequent impact on income distribution:

1. The modern-sector enlargement typology in which two-sector economy develops by enlarging the size of modern sector. While maintaining constant wages in both sectors

${ }^{1}$ Department of Forests, Nepal.

* Corresponding author: anuj128@gmail.com 
as depicted by the Lewis model, the authors have attempted to assess effect on income distribution, eg. development of enterprises or rapid industrialization due to forward and backward linkages of community forestry development in Nepal; one real example of modern sector enlargement in community forestry is presented in box 1 .

2. The modern sector enrichment growth typology, in which the economy grows but such growth is limited to a fixed number of households in modern sector, with both the numbers of farmers and their incomes held constant in the traditional sector, eg. development of industries like saw-mill due to forward linkages of community forestry.

3. Traditional sector enrichment growth typology, in which all the benefits of growth are divided among traditional sector households, with little or no growth occurring in the modern sector. This process roughly describes the increased production of cereal crops and livestock due to increased availability of farm-inputs (leaf-litters, fodder etc) from the community forests. It helps in policies focused on achieving substantial reductions in absolute poverty even at very low incomes and with relatively low growth rates.

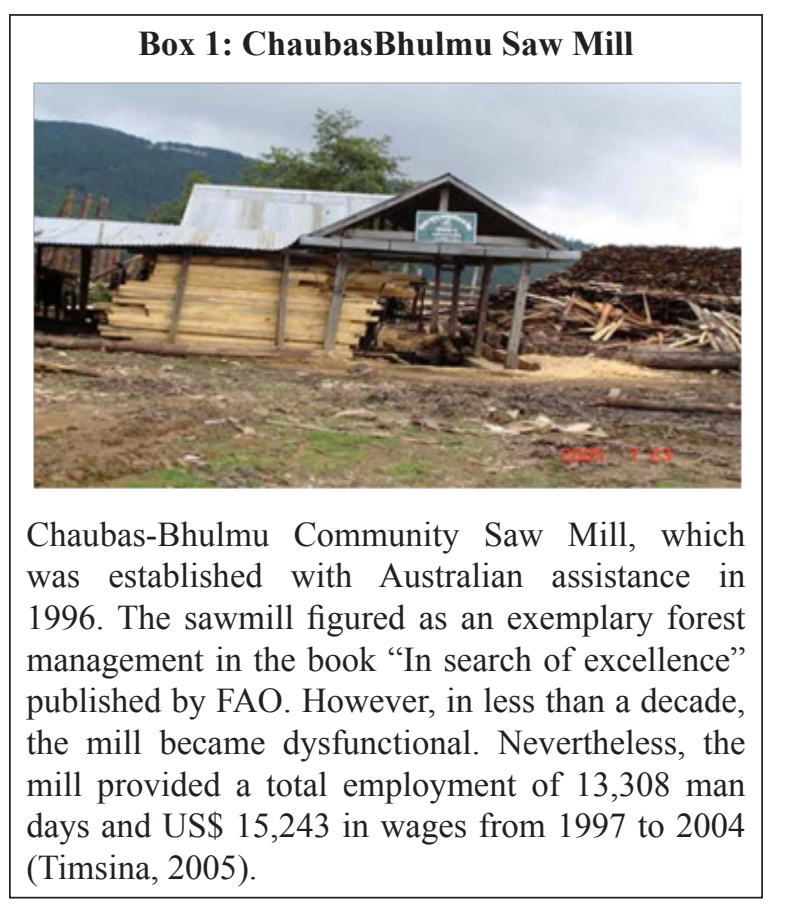

\section{Reflections}

The authors have attempted to use three stylized cases and Lorenz curves to demonstrate the validity of the following propositions. They have just reversed the order presented above.

1. In the traditional-sector enrichment typology, growth in the traditional sector results in higher income of farming households. It leads to a more equal relative distribution of income, and that culminates into reduced poverty. Thus, the traditional-sector enrichment growth ultimately causes Lorenz Curve to shift uniformly towards the line of equality. It shifts closer toward the line of equality, as portrayed in figure 1 which explains reduced poverty with traditional sector enrichment.

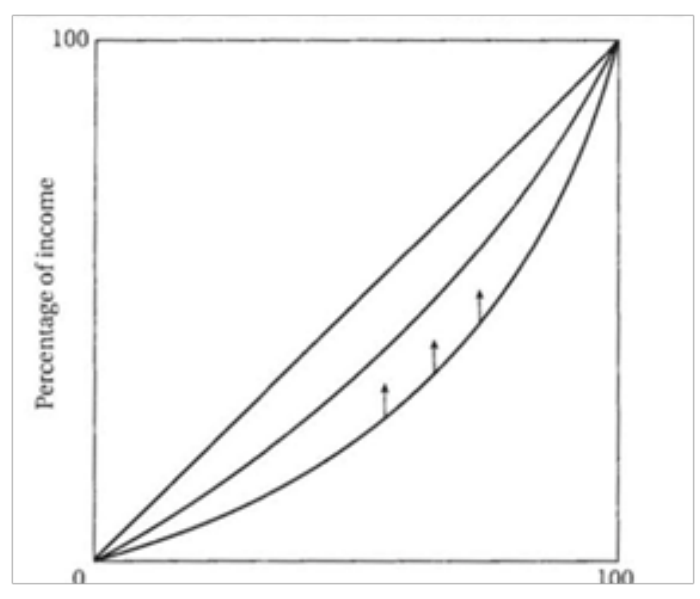

Percentage of income recipient households

Fig.1: Traditional-sector enrichment and consequent poverty reduction (Modified from Todaro and Smith, 2004)

2. In the modern-sector enrichment growth typology, growth results in higher incomes of households in urban areas. However, it leads to a less equal relative distribution of income among the urban and rural sector. It will produce no change in poverty. Modern-sector enrichment growth causes the Lorenz Curve to shift downward and farther from the line of equality as shown in figure 2 . This aggravates inequality with households with lower scale of income and having reduced share of income which will either have no effect or aggravate poverty. 


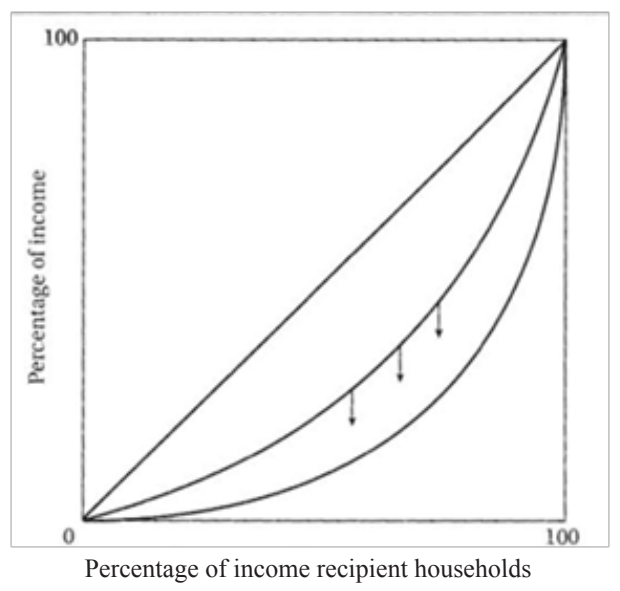

Fig. 2: Modern-sector enrichment with no change in poverty or even aggravated poverty (Modified from Todaro and Smith, 2004)

3. Finally, in the case of modern-sector enlargement growth propelled by Lewis, absolute income of the urban household rises sharply, and absolute poverty in urban locality is reduced. However, the Lorenz Curve will always cross somewhere in the midway so that we cannot make unambiguous statement about the changes in relative inequality among the households. The inequality in income distribution may improve or worsen at the long run. According to Fields, if this style of growth experience is predominant, inequality is likely first to worsen in the early stages of development and then to improve at later stages which is more similar to Kuznets' inverted $U$ hypothesis. The crossings of the Lorenz Curve as suggested by Fields is demonstrated in figure 3 .

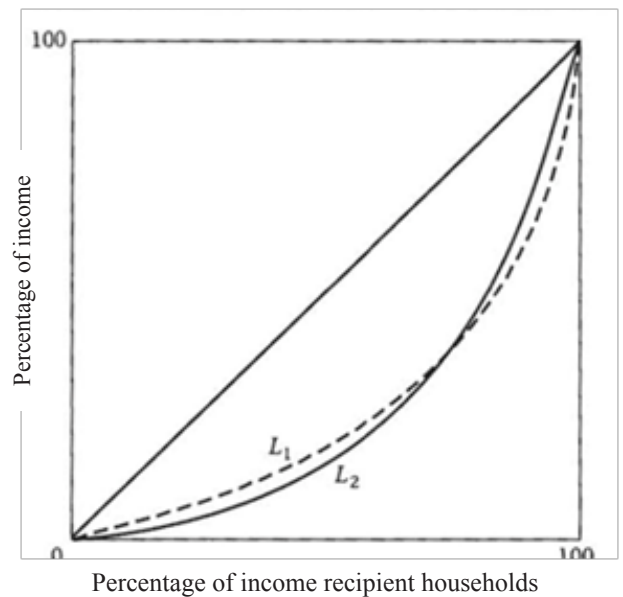

Fig. 3: Modern-sector enlargement with initial aggravation and subsequent reduction of poverty
We can give the explanation for the crossing of the Lorenz Curves in figure 3 as follows:

The poor households who remain in the traditional sector have their incomes unchanged, mainly because there are no investments of development fund in this sector. Hence, these incomes now represent a smaller fraction of the larger total income accrued due to modern sector enlargement. So the new Lorenz Curve, L2, lies below the old Lorenz Curve, L1, at the lower end of income distribution scale. Each modern-sector household receives the same absolute income as before, but now the share received by the richest income group is smaller than before. It explains why the new Lorenz curve lies above the old one at the higher end of income distribution scale. Hence, it can be safely interpreted that somewhere in the middle of the distribution, the old and new Lorenz Curves must cross each other.

\section{Conclusion}

These three typologies offer different predictions about what will happen to inequality in the course of economic growth in community forestry. With modern-sector enrichment, inequality would rise steadily, while under traditionalsector enrichment, inequality would fall steadily and under such circumstances, allocating the development fund for purposes of traditional sector enrichment might be a better option. In contrast, under modern-sector enlargement, inequality would first rise and then fall. If this admittedly highly-stylized process of development were occurring, we would not be concerned about the temporary rise in inequality for two reasons. Firstly, in addition to being temporary, it would be reflecting a process rather than the phenomenon itself. Secondly, increased resources availed due to community forestry will result in a situation in which the member households of forest user group are, one by one, achieving incomes above the poverty line.

These observations tell us that we have to come to conclusion that inequality is bad in general sense. In particular, in some cases, inequality may increase on temporary basis as we have observed in the case of modern-sector enlargement growth. It is due to the causes that will eventually make everyone better off and ultimately lower inequality in the long run. On the other hand, with modern-sector enrichment growth, the 
increase in inequality is not later reversed, and the poorest households of the forest user group do not escape from their poverty. As a result, we need to be careful about drawing conclusion from short-run changes in economic statistics of community forestry before we get insights about the underlying changes in the real economy that have given rise to these statistics. The process of modern-sector enlargement growth suggests a possible mechanism that could give rise to Kuznets "inverted-U" hypothesis which has been established in the course of development; however, the hypothesis itself is disputable.

Different theoretical perspectives on dualistic development suggest different ways of allocating such a development fund. Those who follow Lewis, Fei and Ranis, Jorgenson and others might tend to regard modern sector as the leading sector and the trade as the engine of growth. If this path is followed establishing a sawmill or pole treatment plant at Panchkhal can be a good option to be pursued in community forestry. The underlying assumption is that the best use of additional development resources is to stimulate the modern sector, thereby achieving export-led growth. While the others believing traditional sector enrichment would tend to argue just opposite. If we follow Schultz and Adelman, we are inclined to believe that traditional sector (agriculture) has been deprived of resources and availability of community forests and will complement the resources need of this sector. An influx of development fund in traditional sector would have a higher marginal product than in the modern sector besides reducing risk of higher unemployment (search unemployment) in the latter sector due to crowding effect. It ultimately leads to aggravating unemployment in urban areas while simultaneously lowering output in rural areas.

Those who favor Panchkhal pole treatment plant and advocate development resources to the modern sector tend to presume that economic growth is best achieved by shifting the locus of economic activity towards modern sector activities. The crux of development of modern sector lies on a number of assumptions: the marginal product of additional resources allocated to the modern sector is high; the labour required for production expansion is available; the additional products have market; merely little output is foregone, and, finally, job opportunities will attract job seekers that aggravate unemployment.

At the other end of the spectrum, the proponents of DFID's compost making training to the farmers to enhance agriculture, presume that economic growth is best achieved by targeting economic activity in traditional sector which is starving for additional resources. The cruxes of argument; marginal product of additional resources allocated to the traditional sector is high; plenty of labour available (underemployment); increased agriproducts have multiplier effect on the local economy; market is ensured and investment in agriculture ensures holistic development of the economy.

The preferred allocation of development resources between sectors visibly depend on the amount of modern sector enlargement and traditional sector enrichment that could be achieved under alternative resources allocations and structure of labour market. One of the practical significances of initiating such a discussion is as follows: Using additional development resources to expand modern sector exports and employment is most efficient when marginal product of the capital in modern sector is high and trend of migration is low. At the other paradigm, when the marginal product of capital is higher in the traditional sector as compared to modern sector and wide-spread unemployment/underemployment, allocating development fund for enrichment of the traditional sector might be a better option.

On the eve of sixth national community forestry workshop, a policy discourse is much needed for the destination of community forestry: traditional sector enrichment or modern sector enlargement? It requires discourse and, perhaps, only the stakeholders of community forestry will be able to direct - an answer at this point is beyond the scope of this paper.

\section{References}

Gary, S. B. 1992. Modern sector enlargement or traditional sector enrichment? GNP effects with induced migration. Population Economics 5 (3): 185-201.

GoN, 2013. Public Statement on Income and Expenditure for the Fiscal Year 2013-14. Ministry of Finance, Nepal. http://www. mof.gov.np/ajw/uploads/uploaded_imagel Budget\%20Speech\%2014\%20July\%20 
2013\%20Final\%20review\%2015\%20July. $p d f$

Timsina, N. P. 2005. Supporting Livelihoods through Employment: The ChaubasBhumlu Community Sawmill, Nepal. ITTO, Forest Trends, RECOFTC, Rights and Resources.

Todaro, M. P. and Smith, C. S. 2004. Economic Development. 8th edition. Pearson Education, India. . 